\title{
Processos de significação na relação professor-alunos: uma perspectiva sociocultural construtivista
}

\author{
Maria Carmen Villela Rosa Tacca \\ Angela Uchoa Branco \\ Universidade de Brasília
}

\begin{abstract}
Resumo
Neste artigo consideramos que o fracasso escolar é um fenômeno persistente que exige análises empíricas e teóricas acerca dos processos de significação envolvidos na dinâmica das interações professor-aluno relacionados com as relações ensino-aprendizagem. Com base na abordagem sociocultural construtivista, o estudo analisa a interação de fatores socioculturais com a participação ativa do indivíduo, destacando a unidade cognição-afeto. Os processos interativos atuam como mobilizadores da construção do conhecimento ao longo de convergências e divergências nas interações, especialmente nas negociações quanto aos objetivos e desenvolvimento de atividades pedagógicas. Duas turmas de segunda série do ensino fundamental foram investigadas, sendo destacados os resultados de análises microgenéticas das interações, que apontaram para crenças e estratégias comunicativas e metacomunicativas que podem favorecer ou dificultar o processo de ensino-aprendizagem. A conclusão aponta para o fato dos processos de significação estarem apoiados na metacomunicação e na unidade cognição-afeto, que direcionam as possibilidades de aprendizagem.
\end{abstract}

Palavras-chave: significação; professor-aluno; aprendizagem; construção do conhecimento; fracasso escolar

\begin{abstract}
Meaning processes in the relationship teacher-students: a sociocultural and constructivist point of view. School failure consists of a persistent problem in our educational system. This paper aims at contributing to understand the issue by presenting and theoretically discussing empirical data concerning the dynamics of teacher-students interactions. We draw our analysis on a constructivist sociocultural theoretical framework, which stresses the interactions between sociocultural factors and human agency, claiming for the unison, intertwined nature of affect and cognition. Interactive processes lie at the basis of knowledge construction, which takes place along convergent and divergent interaction frames, particularly during negotiations about goals and rules for educational activities. Two second-grade classrooms were investigated, the results of microgenetic analysis being especially highlighted and discussed. We show how communicative and metacommunicative strategies, together with teacher beliefs, may promote or inhibit teaching-learning processes. We conclude by discussing how meaning construction processes are profoundly intermingled with the affective-cognitive dimension of human development, and how it may decisively contribute to learning possibilities.
\end{abstract}

Keywords: meaning; teacher-student; learning; knowledge construction; school failure

$\mathrm{N}$ presente artigo, interessa-nos analisar as relações entre interações sociais, processos de significação e o fracasso escolar, à luz de uma perspectiva teórica que vem sendo denominada como sociocultural construtivista (Valsiner, 1989, 1994, 2001). Para tanto, serão apresentadas e discutidas questões teórico-metodológicas, bem como dados referentes a um estudo empírico realizado com base em metodologia microgenética.

Quando a literatura trata da questão do fracasso escolar, os trabalhos apresentados, em sua grande maioria, são realizados na escola pública. Esse fato explica-se pelo compromisso político dos pesquisadores com a clientela, que, diferentemente da escola particular, atende principalmente crianças das classes menos favorecidas da população. A exigência da qualidade da educação para todos exige a investigação dos fatores e das circunstâncias que implicam no fracasso escolar na escola pública, ainda tão persistente.

Uma vez que o fracasso é uma realidade mais contundente para quem freqüenta a rede pública (Leite \& Molina, 2002; Silva \& Tunes, 1999; Tacca, 1999), o insucesso passa a ser analisado como um fenômeno inerente à classe social de baixa renda, como se houvesse nela alguma deficiência, tornando-a incapaz ou dificultando-lhe o acesso à escolarização formal. A precária 
situação econômica implicaria diferentes tipos de privação, principalmente de contato com o mundo da leitura e escrita, o que redundaria em sérias e múltiplas limitações diante das exigências que a escola faz. Entretanto, não podemos concluir que esta é uma situação característica de toda uma classe social, pois tal conclusão desconsidera toda a trama de condicionantes que perpetuam os problemas e limitações impostos a essa população, e que acabam por impedir, mais do que facilitar, a continuidade de sua escolarização.

Muitas pesquisas já foram empreendidas (Cagliari, 1989; Carraher, 1990; Moysés \& Collares, 1992; Patto, 2000) com a expectativa de desconstruir os mitos criados a respeito das crianças, seu desenvolvimento cognitivo, suas famílias e a condição de pobreza da classe de baixa renda. Tais trabalhos concluem que o fracasso, de fato, se localiza nesta classe social, mas, absolutamente, ele não é um fracasso inerente a esta população (Charlot, 2000).

As relações que as escolas estabelecem com seus alunos, desde sua chegada à escolarização básica, têm favorecido situações de ruptura. As avaliações que são impostas, as expectativas criadas, aliadas a preconceitos incontestes quanto a idealizações sobre as condições necessárias para a aprendizagem efetiva (Tacca, 1999), fazem com que alunos e professores se olhem, freqüentemente, com desconfiança. Condições idealizadas e profecias auto-realizadoras (Rosenthal \& Jacobson, 1983) geram frustrações, constroem barreiras e tudo isto conduz a um processo de escolarização fadado ao insucesso.

As escolas freqüentemente enfrentam de forma equivocada o aluno que se diferencia em seu saber e em sua forma de aprender (Patto, 2000; Tacca, 1999). Culpabilizam as famílias, e instituem práticas de recuperação de conteúdos, como o "reforço" escolar, que pode acontecer na própria escola, ou serviços especializados. Os resultados, porém, são pouco expressivos, gerando a necessidade de investigação das raízes das dificuldades desses alunos, tais como nos trabalhos de Campos (2005) e Pinheiro (2004), que investigaram o impacto das relações sociais de alunos e professores no processo de aprendizagem na sala de aula.

É inconcebível que crianças sadias e espertas até começarem a educação formal sejam consideradas limitadas e sem condições necessárias para um processo de escolarização bem sucedido. Vários pesquisadores (Carraher, 1990; Moysés \& Collares, 1992; Patto, 2000; Tacca, 1994) vêm denunciado que a escola não se encontra preparada para receber diferentes tipos de alunos, com isto reproduzindo uma organização social excludente, em que a padronização e homogeneização têm lugar de destaque.

Ao tentar ser democrática, ou seja, dar a todos o mesmo tratamento, a escola acaba por cometer inadequações severas, pois não se abre para a perspectiva dos sujeitos concretos, com suas diferentes formas de ser e pensar, sejam alunos ou professores. Continua, pois, atual e urgente, uma permanente reflexão das relações de ensino-aprendizagem que ocorrem no âmbito dos processos interativos da sala de aula, envolvendo alunos e professores. A sociologia da educação nos aponta o papel reprodutor das desigualdades sociais da escola (Bourdieu $\&$ Passeron, 1975), mas é preciso que se vá além, como alguns têm feito (Tacca, 2000), particularmente no que tange à estrutura dos ambientes de aprendizagem (atividades) e à dinâmica das interações sociais no contexto educativo.

Para Vygotsky (1987), a condição humana da pessoa tem origem nas relações sociais, pois são a partir destas que as funções psíquicas superiores são inauguradas. A participação do outro social é crucial na apropriação do conhecimento que possibilita o desencadear dessas funções. Na aprendizagem escolar, inserem-se, de forma deliberada e sistemática, as ferramentas simbólicas e culturais que criam as condições para apropriações e reelaborações do conhecimento pelo sujeito. Este aprende interativamente, e com isto surgem novas possibilidades em seu desenvolvimento. Não há dúvida, portanto, sobre o caráter fundamental das relações estabelecidas entre professores e alunos.

Analisar os processos de significação na relação ensinoaprendizagem, que emergem de redes de significação (RossettiFerreira, Carvalho, Amorim, \& Silva, 2004), consiste em perspectiva produtiva, no sentido de gerar novas contribuições que venham intervir positivamente na tarefa de professores e alunos. É neste contexto que o trabalho aqui apresentado deve ser compreendido. As interações sociais em sala de aula foram analisadas em nível microgenético (Siegler \& Crowley, 1991), particularmente as interações entre a professora e alunos, por ela indicados, com atrasos no processo de escolarização. O foco esteve nos processos mediadores conduzidos pela professora em situações de ensino-aprendizagem, os quais implicavam em diferentes processos de significação por parte do aluno. Tais processos tendiam para modos de significação que, por sua vez, orientavam a criança a construir diferentes tipos de conhecimento. Em outras palavras, nem sempre as crianças aprendem aquilo que supostamente a professora thes ensina, seja em termos de conteúdos, ou em termos de conhecimentos acerca de si e do mundo à sua volta.

Entendemos que análises dessa natureza podem trazer uma valiosa contribuição para o avanço da compreensão dos processos de aprendizagem que ocorrem na intrincada rede de relações da sala de aula, no sentido de mostrar caminhos na direção da superação do fracasso escolar. Enfatizamos, também, a necessidade de trabalhar a dinâmica da unidade cognição-afeto no processo de ensinar e aprender, e o quanto isso é importante para uma aprendizagem que permita ao aluno se sentir competente e se desenvolver de forma plena, integral.

A unidade cognição-afeto está proposta nos trabalhos de Vygotski (1983) quando ele identifica em sua abordagem dialética que o intelecto e o afeto têm regularidades internas que pedem um funcionamento integrado e que, perder essa integração ou dividir essa unidade em seus elementos significa perder as propriedades inerentes ao todo. Assim não há motivação sem pensamento, assim como é impossível um pensamento não motivado.

Estudar, assim, processos de significação inclui conhecer quais as dinâmicas que, na relação professor e aluno, movimentam o processo de aprendizagem. Isso implica olhar o processo interativo na história de sua construção, compreendendo como se movimenta a dinâmica da unidade cognição e do afeto.

Assim as emoções, necessidades e pensamento, tanto de alunos como de seus professores, precisam ser mobilizadas positivamente, e na direção das atividades escolares e dos 
objetivos educacionais. Isso diminuirá a possibilidade de que os processos de significação sejam canalizados em outras direções, que acabam por afastar os sujeitos de uma participação comprometida com sua própria aprendizagem e desenvolvimento.

\section{A co-construção do conhecimento no contexto sociocultural}

A co-construção de conhecimentos deve ser considerada como um processo dinâmico e plural, do qual participam inúmeros fatores complexamente organizados. Com base na abordagem histórico-cultural de Vygotsky e contribuições de Piaget, Valsiner $(1989,1994,2001)$ conceitua cultura como um elemento presente tanto na ação de adultos (que providenciam o ajustamento do ambiente às necessidades da criança, de acordo com suas crenças e valores) como, também, na ação da criança (que vai ativamente significando as mensagens que the chegam). A criança vai aos poucos compreendendo o significado dos sistemas culturais que caracterizam o que Valsiner chama de cultura coletiva. Entretanto, co-constrói esses significados de maneira ativa e singular, constituindo a sua cultura pessoal. Valsiner (1994) faz uma diferenciação entre uma perspectiva unidirecional e bidirecional dos processos de socialização. $\mathrm{Na}$ primeira, existe a suposição de que é possível transmitir às crianças crenças, normas e habilidades específicas, como forma de garantir a inserção da criança no grupo social. A perspectiva bidirecional, porém, reconhece e enfatiza a reconstrução ativa, pela criança, das mensagens culturais. O esforço para socializar a criança, de acordo com os padrões culturais do grupo, é sempre modificado, em maior ou menor grau, pelo papel ativo por ela desempenhado. Os pais e as demais pessoas que participam do universo da criança exercem diferentes papéis, mas é a participação ativa da criança que lhe permite ir além do que the é sugerido (ou imposto) culturalmente. Por meio dos processos de internalização e externalização, ela vai re-significando o conhecimento, o que torna o desenvolvimento de cada sujeito sempre um fenômeno original. O objetivo principal do enfoque co-construtivista na Psicologia, pois, é identificar e analisar os processos que estão envolvidos na constituição da cultura pessoal, considerando a direção canalizadora da cultura coletiva.

Nas relações indivíduo-sociocultura, surge a cultura pessoal que integra fatores cognitivos, emocionais e sociais. A participação em uma sociedade, que institui símbolos e suas significações, leva o indivíduo a uma reorganização constante da cultura pessoal, dando um caráter dinâmico à configuração de sua personalidade (Gonzalez Rey, 2005; Valsiner, 1989, 2001). Novas necessidades induzem novas construções semióticas, em um movimento contínuo, permanente.

Tacca (2000) salienta que, no contexto da sala de aula, quando o professor comunica qualquer mensagem, cada aluno vai recebê-la significando-a de um modo específico, muitas vezes bem diferente. A força do impacto dessa mensagem sobre cada aluno só poderá ser compreendida por ele mesmo. O impacto sobre o grupo, por sua vez, só será compreendido por aqueles que são membros do próprio grupo, ou então, por alguém que se inclua nele por um tempo suficiente que lhe permita perceber o clima e o sentido das relações ali estabelecidas. Retomando o conceito de internalização de Vygotsky, Branco e Madureira (no prelo) propõem uma concepção sociogenética em que os processos de internalização são dinâmicos, orientados pela canalização cultural, porém impregnados da participação ativa do sujeito no processo. Diferentes pesquisas (Branco \& Madureira, no prelo; Branco, Pessina, Flores, \& Salomão, 2004; Tacca \& Branco, 2003) também analisam as situações interativas de ensino-aprendizagem, e a forma como professores e alunos co-constroem os conteúdos e significados escolares, bem como crenças e valores sociais.

Para decifrar a gênese dos processos de desenvolvimento é necessário decifrar os processos interativos, comunicativos e metacomunicativos, que ocorrem nos diferentes momentos e espaços em que os sujeitos se encontram. Por metacomunicativos entendemos a comunicação sobre a própria comunicação, em termos das interações e relações entre os participantes (Branco et al., 2004). Para isso, impõe-se o estudo das dinâmicas interativas, de onde surge o desafio metodológico de construir estratégias adequadas para investigar fenômenos de natureza dinâmica e complexa (Branco \& Valsiner, 1997). Se quisermos compreender como as interações entre professores e alunos levam a significações convergentes ou divergentes, precisamos analisar a dinâmica de suas interações e relações construindo uma abordagem metodológica adequada a este objetivo.

\section{Os processos de significação no contexto educativo}

Enfocar as interações sociais na busca da compreensão de situações nas quais se desenvolve um processo ensinoaprendizagem bem sucedido, relacionando isto a processos de significação do conhecimento por parte do aluno, exige que sejam analisados os aspectos motivacionais que permitem perceber se o aluno está disposto a dar atenção e se empenhar nas atividades propostas pelo professor.

Para atingir os aspectos motivacionais do aluno, torna-se imprescindível considerar, na seleção de objetivos, conteúdos, atividades e métodos de ensino, o quanto isso tudo constitui aspectos mobilizadores para eles. Isso inclui observar os alunos em suas características pessoais, o seu grupo sociocultural, buscando integrar os seus valores, crenças e ideais com aqueles pressupostos nos currículos escolares.

No processo de co-construção do conhecimento, a análise das interações estabelecidas é discutida no espaço da convergência e divergência em relação aos objetivos propostos (goal orientations) que integram os aspectos intelectuais e motivacionais, e estão continuamente sendo elaborados e transformados pelos indivíduos em suas interações (Branco \& Valsiner, 1997). Convergência e divergência refletem a existência de uma compatibilidade ou incompatibilidade entre as orientações para objetivo de cada um dos indivíduos em interação em um contexto determinado. No caso da incompatibilidade, poderá ocorrer uma busca ou movimento em direção à convergência, sendo isto realizado através de negociações.

A perspectiva sociocultural construtivista argumenta que é preciso atentar para como as orientações para objetivo (goal orientation) se articulam, direcionando as atividades no sentido da convergência, da divergência e da ambivalência (Branco \& Valsiner, 1997; Tacca, 2000). Esses processos são vistos 
como continuamente negociados, levando em consideração o contexto sociocultural mais amplo, as características pessoais de cada participante e os aspectos relacionais que são criados no contexto da sala de aula. Nas negociações que aí ocorrem, sempre haverá a necessidade de compartilhamento para a construção do conhecimento, pois o jogo de construção conjunta do conhecimento permite aos indivíduos assumir, não assumir, ou assumir apenas em parte as perspectivas, sugestões ou objetivos dos outros, em uma contínua negociação que pode levar a novas formas do conhecimento culturalmente acumulado. Nesta negociação os processos de comunicação, em seus níveis comunicativo e metacomunicativo, têm um papel fundamental (Maciel, Branco, \& Valsiner, 2004).

Nessa discussão fica claro que a aprendizagem acontece na troca entre os atores envolvidos em um processo intersubjetivo permeado de simbolismos e significações. $\mathrm{O}$ aluno é ativo na elaboração dos conteúdos escolares, cabendo ao professor identificar e analisar os significados que cada um (professor e alunos) atribui aos procedimentos e conteúdos que circulam na sala de aula, nas atividades programadas e no dia-a-dia da convivência entre eles.

É nesse contexto que se inscrevem importantes questões a respeito dos processos de significação, ou seja, de como as interações sociais que têm lugar no espaço educativo favorecem as trocas do aluno com o objeto do conhecimento, e permitem ao estudante apropriar-se da cultura acumulada. Existe uma diversidade de possibilidades na configuração do objeto de conhecimento e de constituição do sujeito aprendiz, unindo-se a uma multiplicidade de processos de significação, na prática interativa e comunicativa da sala de aula. Isso nos permite evidenciar a impossibilidade de um funcionamento homogêneo e prevalente dos sujeitos, que corresponda a construções convergentes na produção de sentido e nos processos de significação.

Compreendemos o

processo de significação como um processo abrangente, no qual emergem motivações, referências, significados e sentidos no contexto de interações (entre pessoas ou entre professor e alunos), nos diferentes lugares e situações (de ensinoaprendizagem). O processo de significação é um processo dos sujeitos implicados nas situações interativas, vistos como sujeitos concretos, situados num momento ontogenético, cultural e histórico, num tempo determinado (Tacca, 2000, p.41).

Um campo de investigação se abre na tentativa de compreender esta trama interativa na qual os processos de significação emergem. Nesta direção, se insere o presente trabalho.

\section{Interação professor-aluno: um estudo qualitativo}

O objetivo do trabalho foi identificar e analisar, na dinâmica das interações de cada professora com os alunos, e no contexto de atividades de ensino-aprendizagem especificamente estruturadas e dirigidas por elas, os processos de significação dos alunos em relação a diferentes aspectos da experiência escolar (Tacca, 2000). O foco recaiu sobre duas professoras de segunda série da educação básica, no Distrito Federal, em interação com um grupo de alunos considerados por elas como atrasados em termos de escolarização. Foram observados os processos comunicativos e metacomunicativos, as estratégias pedagógicas mediadoras utilizadas pela professora, as relações com o saber que eram possibilitadas, incluídas nas diferentes formas de interação verbal e não-verbal no contexto da sala de aula ou em atividades especificamente estruturadas para a pesquisa.

A metodologia qualitativa foi adotada, visto que assume um curso flexível, aberto e progressivo, que permite que construções e interpretações façam avançar possíveis construções teóricas (Bauer \& Gaskell, 2002; González Rey, 1997, 2005). Além disso, nosso objetivo requeria uma análise microgenética das interações gravadas em vídeo no contexto das salas de aula.

A turma da professora Vilma (44 anos; nomes fictícios), tinha 23 alunos e a turma da professora Yolanda (36 anos) tinha 33 alunos. Inicialmente, as turmas foram observadas com diário de campo, no contexto de suas atividades diárias, o que permitiu a mútua e necessária familiarização. Estas foram ricas informações que auxiliaram, posteriormente, no processo de análise microgenética das gravações. Os procedimentos incluíram: (1) observações em sala de aula; (2) uma entrevista inicial com a professora; (3) "atividades estruturadas", realizadas em três sessões com um pequeno grupo de alunos selecionados pela professora segundo o critério de dificuldade de aprendizagem; (4) grupo de discussão, composto pelos alunos participantes das "atividades", pela professora e pela pesquisadora, para avaliação das sessões; e (5) uma entrevista final com a professora.

As três sessões foram "estruturadas" visando: a primeira, a privilegiar interações da professora com o grupo todo; na segunda, os alunos deveriam trabalhar entre si com sua supervisão; e a terceira sessão deveria ser estruturada para promover interações diádicas professora-aluno.

Vilma selecionou quatro alunos (três meninos e uma menina). Três eram repetentes e o outro, apresentava dificuldades em leitura e escrita, e problemas de comportamento. Yolanda selecionou três alunos (duas meninas e um menino) para participar das "atividades estruturadas", incluindo também um menino e uma menina um pouco mais adiantados (no total, cinco alunos). Tendo em vista o reduzido espaço, optou-se neste artigo pela apresentação de alguns dos dados construídos com base no estudo microgenético das interações que ocorreram durantes as sessões estruturadas, gravadas em vídeo.

Com Vilma, as atividades estruturadas desenvolveram-se em quatro dias consecutivos, o quarto dia dedicado à avaliação pelo grupo. Cada sessão durou, aproximadamente, uma hora. Yolanda realizou o trabalho em três dias sucessivos, incluindo a sessão de avaliação grupal. Ambas se empenharam em colaborar em todas as etapas do trabalho. As gravações em vídeo (sessões) e em áudio (entrevistas) foram minuciosamente transcritas e analisadas.

Depois de repetidas observações dos vídeos e leitura atenta das transcrições, foram selecionados para análise microgenética os episódios que, dado seu conteúdo, evidenciavam e permitiam a análise dos processos de significação das crianças. Os padrões 
interativos ali observados possibilitaram verificar e confirmar hipóteses e interpretações sobre os processos de significação presentes nas interações. A seguir, este artigo é ilustrado com um episódio selecionado de cada professora.

\section{Processos de significação da aprendizagem: Vilma e seus alunos}

Na primeira sessão, Vilma trouxe um resumo da fábula $A$ cigarra e a formiga. Depois de lerem o texto, os alunos deveriam realizar exercícios de interpretação, e ao final, deviam fazer uma redação. O episódio aqui analisado foi extraído da segunda sessão, que durou uma hora. A professora havia solicitado como dever de casa que as crianças pesquisassem sobre curiosidades acerca de cigarras e formigas. O episódio iniciou-se com Vilma (V) cobrando o dever de casa:

1. V: O que foi que vocês encontraram de curiosidade?

2. João Paulo: Eu só encontrei uma coisa. Uma coisa de cada vez.

3. Lúcia: Eu procurei, não achei.

4. V: Só você que encontrou, João Paulo?

5. João Paulo: Mas eu não encontrei, foi o que eu entendi do texto que eu botei aqui.

6. V: Sim, mas eu pedi pra vocês fazerem uma pesquisa. Vocês não trouxeram nada? (fala destacando a palavra "nada")

7. João Paulo: Eu fiz dos dois lados: a cigarra eu botei... a cigarra aqui..., do outro lado tem a formiga... Eu pensei que eu fosse encontrar mais coisa...

João Paulo, enquanto fala, vai até V e lhe entrega a folha de papel com o resultado da sua pesquisa. $V$ olha o que ele entrega e lhe devolve em seguida, dizendo sem entusiasmo:

8. V: Hãhã... Tá... Ok, João Paulo.

João Paulo volta para seu lugar e se senta, colocando a folha com as anotações de sua pesquisa debaixo da carteira. V tem algumas folhas de papel na mão (fotocópias de páginas de uma enciclopédia onde ela encontrou informações sobre a cigarra e a formiga).

Logo de início, pode-se perceber a cobrança e a frustração da professora pelo fato das crianças "não terem realizado a pesquisa". No entanto, ela não ouviu ou não deu importância à Lúcia, que disse que havia procurado e não achado (turno 3), e desqualificou o trabalho de João Paulo. Ela também não se deteve a perguntar a Roberto e Elizer porque não haviam trazido alguma informação. A sua ênfase na palavra nada, no turno seis, continha claras indicações de que ela se sentiu desconsiderada. Na prática, porém, ela já tinha decidido utilizar o texto que trouxe, para realizar a atividade com os alunos. O texto era fotocópia de uma enciclopédia e continha as informações, mas em uma redação prolixa, densa de informações e conceitos científicos.

A maneira de a professora utilizar o texto, ou seja, fazendo uma leitura contínua sem olhar para as crianças, tropeçando em algumas palavras, sugeria que ela mesma estava entrando em contato com aquelas informações pela primeira vez. Ela tinha nas mãos cópias de páginas retiradas de uma enciclopédia e não um texto preparado para a ocasião. Era um texto com linguagem rebuscada que ela lia, detendo-se, às vezes, em algumas palavras, explicando-as de forma superficial. Muitas outras ficavam sem explicação, ou eram explicadas de forma duvidosa e insegura. Se as crianças perguntavam, ela respondia com base na leitura feita no momento ou com base no senso comum Os indicadores nãoverbais e verbais, ou seja, o tom de voz, gestos de impaciência e respostas evasivas, desconexas e inconclusivas sugeriam insegurança, irritação e incerteza por parte da professora. O dois trechos abaixo ilustram bem as dificuldades da tarefa, quando explicações sobre a cigarra estavam em foco:

1. V: “...o tórax é grande, as asas são membranosas...”. Membranosas vem de membrana. ...ela tem aqui, dos ladinhos dela, o órgão estribulante; é .... é o órgão que faz aquele sonzinho... É cada parte do abdômen dela...

2. João Paulo: Então o som sai por aqui dela?

3. V: Humhum...tipo assim...esse som que ela emite quando canta...Como é que se diz... ela tem duas cavidades aqui...

A professora explicava de forma titubeante, o que se evidencia nos turnos um e três. Ela não podia estimular as crianças a perguntar, pois, possivelmente, não teria condições de responder. Essa inferência é feita pela limitada explicação que deu às crianças ou quando se esquivou de abrir um diálogo com João Paulo diante das perguntas que ele fazia. Em vários momentos, este aluno mostrou-se ativo e interessado, levantava a mão, fazia comentários ou chamava a professora, mas ela seguia em frente em sua leitura, sem dar-lhe espaço e atenção (turno três). Mesmo assim, por duas vezes, ele conseguiu colocar suas dúvidas, mas acabou recebendo uma resposta irritada da professora, inferida a partir de sua fisionomia séria, não detendo seu olhar sobre a criança e da inflexão e tom de voz ríspidos (também evidenciados nos turnos dois e quatro, a seguir). Perguntar e participar ativamente da tarefa não era exatamente o que ela parecia esperar de seus alunos, pois a leitura e explicações eram rápidas, as perguntas evitadas e pareciam denunciar, também, que ela precisava chegar logo ao fim daquele momento. Falando sobre a formiga, ocorre o seguinte diálogo:

1. João Paulo: (Levanta a mão, pedindo para falar.) Professora, Vilma...

2. V: Só um minutinho, por favor! Aí tem as fêmeas férteis, que são as rainhas, né? Que são as únicas que põem ovos e se reproduzem... tá? Agora... Tem uma curiosidade sobre elas. É sobre os machos... tá? Os machos são dotados de asinhas. Eles vivem o tempo suficiente apenas para fecundar a rainha. Tá? Depois que eles se acasalam pra ter os filhotinhos o macho morre. A vida dele é bem curtinha...

3. João Paulo: Por que, professora?

4. V: Óh, João Paulo, aqui não explica o porque. (com tom irritado, impaciente) A gente pode até depois fazer uma pesquisa mais apurada pra saber porque. Aqui mesmo não traz o porque. Só diz que quando eles são adultos eles são alados, alados significa que é porque eles têm asas e que eles só vivem o suficiente para a reprodução. Depois que ele fecunda a fêmea ele morre. Aí não tem... a gente pode tentar descobrir. Ok? E... é o que tem assim, de mais importante para o nosso trabalho, tá?

O diálogo acima evidencia o apuro da professora, quando precisou estender suas explicações em vista da curiosidade que 
o assunto despertou. Seria natural que Vilma não tivesse todas as explicações diante das curiosidades dos alunos; no entanto, assumiu uma postura defensiva, na medida em que se justificou que não poderia explicar mais do que o texto lhe permitia e postergou outras explicações para pesquisa mais apurada no futuro. Ela poderia ter feito reflexões, mesmo que fossem apenas apresentadas como especulações, mas que exercitassem o potencial criativo dos alunos. Mas revelou desconforto por não ter respostas prontas e certas, esquivando-se de um diálogo descontraído que levasse a construções conjuntas de idéias e hipóteses interessantes. Para a professora, a experiência de conhecer parecia limitar-se ao conhecimento que está nos livros, envolvendo apenas as informações ali contidas, e que deviam ser reproduzidas na sala de aula. Em resumo, as crianças deveriam se manter passivas e quietas, pois a professora não lhes instigava com perguntas e, assim, elas não eram exercitadas em sua curiosidade.

No prosseguimento da atividade, foram proliferando dúvidas e dificuldades de entendimento do que ela realmente desejava que as crianças fizessem. Ninguém conseguia entender, de fato, o que deveria ser feito, e com toda razão, pois a professora era evasiva e contraditória em suas instruções. Ela dava informações contraditórias e eles indagavam inúmeras vezes: "Professora, está correto, isso aqui?" "Professora, eu vou copiar isso aqui, você acha que dá?”, “Oi, professora, é para eu escrever o mesmo que ele?". Diante dessas perguntas Vilma foi se tornando cada vez mais perdida e irritada, e decidiu responsabilizar as crianças pela falta de entendimento das instruções. Isso foi percebido quando em certo momento disse: "Volta lá, olha lá no texto! Já que vocês não fizeram a leitura com a atenção suficiente...!" e em outra situação: "Vocês não fizeram o dever de casa e, agora, não venham reclamar!" Os objetivos da tarefa proposta, se é que existiam, não podiam ser identificados, e as crianças se empenhavam em adivinhar para agradar a ela, com isto aprendendo (significando) que, numa tarefa de ensinoaprendizagem, o que importa é fazer o que o professor manda. Assim, evitavam ser acusadas, denunciadas como desatentas e/ou incompetentes. Isso tudo gerava uma atmosfera afetiva de antagonismo e aversão que, tornada cotidiana, podia levar à rejeição e ao desinteresse da criança em relação à escola e à aprendizagem.

Os padrões interativos professora-alunos produziam, assim, um clima de incerteza, insegurança e medo, afastando possibilidades de aprendizagens significativas sobre um tema que, em muito, despertava a curiosidade e motivava as crianças. As energias foram canalizadas na direção de significações muito distantes daquelas necessárias e próprias ao contexto escolar, gerando por parte das crianças auto-avaliações negativas acerca de si mesmas que foram claramente reveladas na última sessão (de avaliação em grupo): percebiam-se como "bagunceiras" e incompetentes e assim se expressaram: "Aqui todo mundo é bagunceiro, ninguém é santo" ou "Eu confesso que sou bagunceiro. Eu confesso".

\section{Processos de significação da aprendizagem: Yolanda e seus alunos}

A professora Yolanda escolheu trabalhar com um livro de estória infantil intitulado Se as coisas fossem mães, de Sylvia Orthoff. Era o mês de maio e o momento mostrava-se propício para desenvolver o tema. Na primeira sessão, ela apresentou o livro para as crianças e se deteve na análise do significado da ilustração da capa. Na segunda sessão, ela propôs uma atividade escrita que ampliava as idéias do livro. Desta sessão, extraiu-se o episódio apresentado a seguir.

Yolanda preocupou-se em subsidiar as crianças com elementos conceituais nos quais pudessem apoiar seu pensamento para resolver a tarefa. Dava indicadores que ajudavam as crianças a estabelecer relações com coisas ou experiências já conhecidas ou aprendidas, estimulando-as a desempenhar adequadamente a atividade. Quando a criança pedia auxílio ou ela identificava algum equívoco na tarefa realizada, procurava levar a criança a identificar de forma ativa os seus próprios erros.

No episódio aqui selecionado para análise, as cinco crianças deviam escrever as características físicas das mães (cor de cabelo, olhos, etc). Estavam sentadas em semicírculo quando Rodrigo falou algo muito baixo. A professora Yolanda (Y) se levantou para atendê-lo:

1. Y: Deixa eu ver o que você escreveu aqui, eu vou ler. Pode?

A criança consente com a cabeça e Y lê:

2. Y: O cabelo da minha mãe e o... os... (deixando em suspenso para o aluno completar)

3. Rodrigo: Olios

4. Y: É isso? Espera ai... Olha aqui pra mim, né? Oh... Não é o-li-os (mostra com o dedo próximo aos olhos), é olhos, o-lhos, o- lhos, lhos, lho. O que que tem aí?

5. Rodrigo: Ah! Não sei!

6. Y: Sabe sim! O-lhos. (tom de voz firme e estimulante)

Rodrigo apaga e começa escrever de novo, mas $\mathrm{Y}$ o interrompe.

7. Y: Não, peraí! Oh, isso... pára aí, pára, parou... Agora olha pra mim! ( voz tranqüila)

Rodrigo olha para Y:

8. Y: lhê, lhê, lhê (ela enfatiza o fonema na sua fala). Que pedaço é esse?

9. Rodrigo: É o i?

10. Y: Que sílaba?

Rodrigo fica pensando algum tempo. Y prossegue:

11. Y: Tra-ba-lhan-do. O-lho (ela enfatiza e compara as duas palavras)

12. Rodrigo: 1-h

Y balança a cabeça afirmativamente, dando confiança ao aluno e sorrindo diz:

13. Y: Isso, 1-h. Muito bem! Tá vendo como você sabe!

A professora interagiu com a criança analisando a fonética da palavra (turnos quatro, seis, oito e 11). Repetiu várias vezes a sílaba, pedindo que Rodrigo prestasse atenção à sua fala e à sua articulação dos sons; estrategicamente, também usou uma outra palavra para subsidiar a análise da criança (turno 11). Percebe-se que foi, principalmente, o apoio dessa nova palavra, ou a relação que ela permitiu a criança fazer, que auxiliou a identificação do fonema. Yolanda teve o cuidado de utilizar uma palavra em que o fonema $l h$ aparecia acompanhado de outra vogal, o que tornou 
mais clara a sua pronúncia. A insistência para que a própria criança identificasse o fonema indicou seu empenho em que esta participasse ativamente do processo de descoberta da escrita da palavra, com o seu auxílio.

Yolanda não indicava, simplesmente, a grafia correta, mas subsidiava a criança com relações pertinentes que a ajudavam a ir além da palavra específica. Com isto, ampliava os processos de significação da criança. Apoiava o processo de pensamento da criança ao estimulá-la a encontrar caminhos para transpor as dificuldades e encontrar soluções por si mesma. Havia no clima afetivo da relação, observado nos indicadores não-verbais e pelas estratégias metacomunicativas, a consideração de que a criança era capaz (turno seis) e que ela estava ali para auxiliá-la a construir a "novidade". Os indicadores verbais e não-verbais, ao longo dos processos metacomunicativos, criavam um clima de confiança mútua muito claro, sem ambigüidades. Alguns exemplos de indicadores verbais que demonstram o respeito dela pela criança incluem, no pequeno trecho acima: solicitar permissão para olhar o trabalho do menino (turno um); criticar de forma afável, justificando sua observação (turno quatro); fazer perguntas específicas para a criança (turno 4); pedir para o menino olhar para ela (turnos quatro e sete); elogiar e confirmar a resposta dada (turno 13); fazer gesto afirmativo com a cabeça, aguardando pacientemente a resposta da criança, abaixando-se para ficar mais perto dela. Em situações semelhantes a essa, mantinha-se calma, voz e gestos tranqüilos embora firmes, demonstrando à criança que ela tinha possibilidades de concluir de forma bem sucedida a atividade. A professora não era permissiva, e regras eram negociadas no dia-a-dia da sala de aula, como por exemplo, todos tinham de finalizar as tarefas que haviam iniciado.

Ao longo das sessões da "atividade estruturada", a professora convidava as crianças a refletir (significar) sobre variados aspectos da situação, que pudessem levar à promoção de aprendizagens efetivas. Dentre outros pequenos detalhes e nuances incorporados ao processo interativo, Yolanda estimulava os alunos a realizarem a tarefa. Destaca-se a forma interrogativa para alertar a criança, induzindo-a a encontrar o próprio erro: "O que está faltando?”, ou pedir que ela lesse o que havia escrito: "Lê para mim". Seu afeto e empatia eram também indicados por palavras no diminutivo, impregnando de significados positivos o momento da aprendizagem. Isto dava leveza às correções que fazia: "Dá uma apagadinha..."; "Fala bem devagarzinho, certinho". Atendia tranquilamente cada criança, pedindo-lhe que cada um esperasse sua vez: "Agora eu tô falando com ele. Já, já eu chego em você. Quando eu chegar em você é só com você que eu vou ficar!". Assim, ia valorizando o trabalho de cada criança.

Nos processos comunicativos entre a professora e seus alunos pairava uma relação de confiança, muito próxima do que McDermott (1977) propôs como elemento essencial, em termos de convergência de orientações para objetivos na aprendizagem (Maciel et al., 2004). Os processos de significação eram impregnados de seriedade, e a importância do aprender exigia muita atenção e calma. Possivelmente, as crianças estavam, ali, se constituindo como sujeitos de possibilidades, seus erros sendo interpretados como espaços para progredir, e não desanimar (Leite \& Molina, 2002). Neste contexto, escola, professora e conteúdos escolares não consistiam em barreiras para o conhecimento, mas sim possibilidades concretas para aprender mais, de forma confiante.

\section{Discutindo processos e interações}

Sobre os processos de comunicação e metacomunicação, foi muito importante identificar o quanto estes estruturam as relações e organizam os espaços de aprendizagem. Na comunicação, cognição e afeto atuam de forma integrada, sendo possível reconhecer sua unidade (Branco et al., 2004), com base na análise das duas turmas. Vilma emitia mensagens explicitas e implícitas (verbais e não-verbais) sobre sua desconfiança em relação à capacidade de atenção e aprendizagem das crianças. Os processos de comunicação eram caracterizados, segundo ela, pela falta de interesse ou pré-requisitos por parte dos alunos (conhecimentos prévios, condições familiares, capacidades intelectuais). Por parte dos alunos, observou-se retraimento, medo, insegurança, e submissão diante da autoridade. Alunos e professora se posicionavam em campos opostos, estando continuamente atentos para evitar maiores desentendimentos. Nas relações de poder ali estabelecidas (Aquino, 1998; Foucault, 1979; Resende, 1995), o lado mais forte acusava - por insegurança e incapacidade de análise - e o mais fraco se defendia, internalizando a menor valia e sua condição de deficiência e inferioridade.

De outro lado, Yolanda apresentava-se bastante construtiva em seus processos comunicativos com os alunos, construindo com eles uma relação de confiança. Cuidadosa nas mensagens implícitas e explícitas, falava com as crianças, mesmo quando corrigia seus erros, considerando que estavam em processo de construção da aprendizagem. A lógica da unidade ensinaraprender pareceu orientá-la a incentivar os alunos a acreditarem em si, e vencerem os obstáculos em uma busca ativa de novos caminhos e soluções. Os processos comunicativos aconteciam em um clima de valorização da criança e do seu trabalho. Os alunos participavam com gosto, sendo freqüentes situações provocadoras de risos. Ao questionar as crianças, Yolanda mostrava-se transparente em seus objetivos e intenções, evidenciando respeito ao grupo. Nas perguntas desafiadoras, não havia indicadores de acusação implícita. $\mathrm{O}$ ambiente social, que envolvia a todos em intrincadas redes de significação (Bruner, 1997; Góes \& Smolka, 1997; Rossetti-Ferreira et al., 2004), se apresentava como especialmente relevante para o desenvolvimento cognitivo e sócio-afetivo do aluno. Em resumo, os alunos de Yolanda pareciam ir se constituindo como sujeitos "competentes", enquanto que os de Vilma, sujeitos "deficientes" (Villas Boas, 1995).

Em relação às estratégias pedagógicas, mediadoras da ação docente, foi possível verificar que ambas tinham recursos e/ou materiais pedagógicos similares. A diferença estava na forma como estes eram utilizados, e em quais atividades eram propostas. Isto é importante destacar porque é muito comum a argumentação de que as condições precárias de materiais e recursos pedagógicos estão na origem dos resultados insatisfatórios das relações ensino-aprendizagem. O que 
diferenciava as professoras não eram os recursos que tinham para trabalhar, mas suas crenças e objetivos. Por exemplo, Vilma utilizou vários recursos como papel, tinta, materiais coloridos, mas sua expectativa era de que as crianças apenas reproduzissem um modelo específico. Para Yolanda, cores e pincéis eram para estimular o pensar e o criar das crianças. Os pressupostos, crenças e valores sobre como deveriam proceder com os alunos, para encaminhá-los rumo aos objetivos desejados, era o que, de fato, distinguia essas professoras.

Vilma afirmou que deixar os objetivos obscuros "estimulava" a criança: "Eu coloquei para confundir. Se eu tivesse colorido, vocês iam adivinhar. Quer dizer, vocês não iam pensar, vocês iam logo sacar o que era..." (sessão do grupo, turnos 148 e 149). Sua lógica parecia ser a seguinte: uma boa atividade precisa ser de difícil compreensão para a criança, pois somente assim elas irão pensar. Yolanda, por sua vez, usava a estratégia da simplificação, pois parecia acreditar na necessidade de as crianças terem clareza sobre o que deveriam realizar. Repetia várias vezes as instruções, de maneiras diferentes, e em seu estilo de mediação pedagógica, freqüentemente fornecia um exemplo claro, e/ou fazia um primeiro exercício junto com os alunos.

Segundo Vygotsky (1991), é importante cuidar para que os conceitos nos quais a aprendizagem se apóia estejam constituídos no aluno. Pode haver rupturas no processo de compreensão de um conteúdo pela falta do apoio de um conceito anterior, comprometendo o aprendizado. O uso de diferentes estratégias na mediação pedagógica, como a utilização de perguntas, pedidos de confirmação e outras, consistem em formas do professor verificar qual base conceitual os alunos já possuem, e quais são os conceitos que necessitam ser esclarecidos, explorados e aprofundados. Yolanda atuava procurando perguntar e esclarecer conceitos, e com isso melhor conhecia as possibilidades das crianças. Promover seus pensamentos perguntando, pedindo confirmação, deixando o aluno completar uma idéia, confirmando-o como sujeito, dando e pedindo exemplos, enfim, ela utilizava vários recursos para interagir e conhecer o pensar da criança.

As concepções do saber, para uma e outra professora, também foram bem distintas. Vilma seguia as orientações padronizadas do sistema de ensino, evitando a todo custo sair do planejamento previamente elaborado, que exercia o controle das ações de si e dos alunos. Observou-se que, para ela, o conhecimento era um conjunto de conteúdos pré-determinados a serem incutidos nas crianças, algo a ser assimilado pronto, fechado e de forma homogênea por todos. Sua prática não envolvia os alunos, mas sim o cumprimento do currículo, não havendo necessidade de as crianças pensarem ou proporem novas idéias: as crianças deviam lembrar (repetir) do que leram, viram ou ouviram da professora.

Yolanda, em sua relação com o saber, afirmou na entrevista que nem sempre cumpria seu planejamento. Nas observações, confirmou-se que incluía atividades e conteúdos não planejados, mas importantes para o momento, o que indica sua sensibilidade ao ritmo dos alunos, bem como a seus interesses e necessidades. Sua atividade docente estava orientada, especialmente, para a promoção do desenvolvimento dos alunos.

\section{Conclusões}

Neste trabalho, destacamos os processos de significação que emergem das interações professor-aluno em contextos de ensinoaprendizagem, com base em uma visão teórico-epistemológica segundo a qual o sujeito e o contexto sociocultural se constituem mutuamente. Foi possível constatar a profunda relação entre crenças, valores e práticas concretas de comunicação e metacomunicação na promoção ou inibição de aprendizagens significativas no contexto escolar. Esta constatação emergiu das análises, microanálises e interpretações dos processos de comunicação, uso de estratégias metacomunicativas e pedagógicas, e as relações de cada professora com o seu papel de promotoras do saber. Em especial, interessou a análise microgenética dos processos de significação no cenário das relações sociais entre professora e alunos. Não foi nossa intenção inicial contrapor as duas professoras, radicalizando posições, pois não acreditamos em receitas ou manuais de "como ser um bom professor", e não pretendemos sugerir uma visão maniqueísta entre concepções e práticas de professores. O que ocorreu foi que as análises que fluíram dos dados acabaram gerando o contraste entre as professoras. Sabemos que cada professor tem seu estilo e concordamos com McDermott (1977) em que o importante não é o "estilo" do professor, mas sim o estabelecimento de uma relação de confiança entre ele e seus aluno. Aprendemos com as duas professoras, entre outras coisas, como as percepções e concepções que orientam os espaços educativos podem ter um impacto considerável sobre os alunos e seus processos de significação de si, do conhecimento e do mundo, em termos abrangentes.

Outro aspecto a ser salientado refere-se ao papel ativo do aluno (Valsiner, 2001), que tem a necessidade de, a partir das trocas interpessoais, dar um sentido pessoal ao conhecimento mediado pelo professor. Ao demonstrar aspectos da dimensão psicológica do fracasso, trouxemos algumas reflexões não somente sobre a prática pedagógica de professores do ensino básico, mas, igualmente, de qualquer professor, em todos os níveis de ensino. São princípios pedagógicos, de relações com o conhecimento e de constituição subjetiva de alunos e professores que, se trabalhados, poderiam favorecer bastante o sucesso dos processos de ensino-aprendizagem.

Entendemos que criar zona de desenvolvimento proximal (Vygotsky, 1991) só é possível quando o sujeito mais experiente atua através de estratégias que, de fato, desafiam o pensamento reflexivo, ou seja, quando o sujeito menos experiente interage não simplesmente com um outro social mais experiente, mas um outro que lhe apresenta apoio emocional e operacional, no sentido de lhe favorecer um salto qualitativo, com base na unidade pensamento-emoção. As estratégias de um bom professor, por diferentes que sejam, devem sempre incentivar as crianças para a aprendizagem que sempre acontece na conjuntura de diferentes processos de significação.

O saber, visto enquanto processo, é gerado nos entrelaçamentos dos saberes que provém das crianças, o que possibilita a promoção do pensamento reflexivo na relação com a realidade a ser aprendida, apreendida. Charlot (2000) afirma que o saber é, em si mesmo, uma relação. Os diferentes saberes, diz o autor, 
aparecem na conjuntura das diferentes relações estabelecidas entre o homem e o mundo. Aprende-se nas relações com o objeto, na participação em atividades, e nos vários tipos de relação com os outros.

Em resumo, é fundamental identificar e analisar os processos que têm por objetivo a promoção de aprendizagens significativas. Muito se diz e se critica sobre o trabalho do professor, mas é preciso colaborar para que todos os educadores percebam a importância de observar e analisar atentamente, em nível microgenético, suas próprias ações e interações, à luz das concepções, crenças e valores que, de fato, orientam suas práticas cotidianas.

\section{Referências}

Aquino, M. de A. (1998). Prática discursiva e construção do sentido na sala de aula. Tese de doutorado não-publicada, Universidade Federal do Rio Grande do Norte, Natal.

Bauer, M. W., \& Gaskell, G. (2002). Pesquisa qualitativa com texto, imagem e som. Petrópolis, RJ: Vozes.

Bourdieu, P., \& Passeron, J. C. (1975). A reprodução: elementos para uma teoria do sistema de ensino. Rio de Janeiro: Francisco Alves.

Branco, A. U., \& Madureira, A. F. (no prelo). Psicologia escolar e diversidade: práticas, crenças e valores na construção de uma cultura democrática. In M. A. Dessen \& D. M. Maciel (Orgs.), Desenvolvimento humano: contribuições para o diálogo entre psicologia e educação. Porto Alegre: ArtMed.

Branco, A. U., Pessina, L., Flores, A., \& Salomão, S. (2004). A sociocultural constructivist approach to metacommunication in child development. In A. U. Branco \& J. Valsiner (Orgs.), Communication and metacommunication in human development (pp. 3-32). Greenwich, Connecticut: Information Age.

Branco, A. U., \& Valsiner, J. (1997). Changing methodologies: A co-constructivist study of goal orientations in social interactions. Psychology and Developing Societies, 9, 35-64.

Bruner, J. (1997). Atos de significação. Porto Alegre: Artes Médicas.

Cagliari, L. C. (1989). Alfabetização e lingüistica. São Paulo: Scipione.

Campos, G. R. de A. (2005). A constituição subjetiva de alunos em situação de fracasso escolar. Dissertação de mestrado não-publicada, Universidade de Brasília, Brasília, DF.

Carraher, T. N. (1990). Na vida dez na escola zero. São Paulo: Cortez.

Charlot, B. (2000). Da relação com o saber: elementos para uma teoria. Porto Alegre: Artes Médicas.

Foucault, M. (1979). Microfísica do poder. Rio de Janeiro: Graal.

Góes, M. C. R., \& Smolka, A. L. B. (1997). A significação nos espaços educacionais: interação social e subjetivação. Campinas: Papirus.

González Rey, F. (1997). Epistemologia cualitativa y subjetividad. Havana: Pueblo y Educación.

González Rey, F. (2005). Subjetividade, complexidade e pesquisa em psicologia. São Paulo: Pioneira Thomson Learning.

Leite, S., \& Molina, A. (2002). Cultura e práticas pedagógicas: a qualidade da mediação e a questão do erro em sala de aula. In S. Leite (Org.), Cultura, cognição e afetividade: a sociedade em movimento (pp. 103-133). São Paulo: Casa do Psicólogo.

Maciel, D. A., Branco, A. U., \& Valsiner, J. (2004). Bidirectional process of knowledge construction in teacher-student transaction. In A. U. Branco \& J. Valsiner (Orgs.), Communication and metacommunication in human development (pp. 109-125). Greenwich, Connecticut: Information Age.

McDermott, R. (1977). Social relations as contexts for learning in schools. Harvard Educational Review, 47(2), 198-213.

Moysés, M. A. A., \& Collares, C. A. L. (1992). A história não contada das dificuldades de aprendizagem: limites e contribuições. CEDES (Campinas), 28, 31-47.

Patto, M. H. S. (2000). A produção do fracasso escolar. São Paulo: Casa do Psicólogo.

Pinheiro, P. M. A. (2004). Sucesso escolar: uma possibilidade na relação professor-aluno. Dissertação de mestrado não-publicada, Universidade de Brasília, Brasília, DF.

Resende, L. M. G. (1995). Relações de poder no cotidiano. Campinas: Papirus.

Rosenthal, R., \& Jacobson, L. (1983). Profecias auto-realizadoras na sala de aula: as expectativas dos professores como determinantes não intencionais da capacidade intelectual dos alunos. In M. H. S. Patto (Org.), Introdução à psicologia escolar (pp. 258-295). São Paulo: T.A. Queiroz.

Rossetti-Ferreira, M. C., Carvalho, A. M., Amorim, K. S., \& Silva, A. P. (2004) Rede de significações: uma nova perspectiva teórico-metodológica. Porto Alegre: Artes Médicas.

Siegler, R. S., \& Crowley, K. (1991). The microgenetic method. American Psychologist, 46(6), 606-620.

Silva, E. G., \& Tunes, E. (1999). Abolindo mocinhos e bandidos: o professor, o ensinar e o aprender. Brasília: Editora da Universidade de Brasília.

Tacca, M. C. V. R. (1994). O sistema de crenças do professor em relação ao sucesso e fracasso de seus alunos. Dissertação de mestrado não-publicada, Universidade de Brasília, Brasília, DF.

Tacca, M. C. V. R. (1999). Professores, suas crenças e a possibilidade de sucesso de seus alunos. Caderno Linhas Críticas (UnB), 5(9), 85-101.

Tacca, M. C. V. R. (2000). Ensinar e aprender: análise de processos de significação na relação professor-aluno em contextos estruturados. Tese de doutorado não-publicada, Universidade de Brasília, Brasília, DF.

Tacca, M. C. V. R., \& Branco, A. U. (2003). Comunicación y metacomunicación en contexto de las situaciones de enseñanza y aprendizaje. Revista de Psicología (Peru), VI(2), 127-145.

Valsiner, J. (1989). Human development and culture: the social nature of personality and its study. Lexington, Massachusetts: Lexington.

Valsiner, J. (1994). Bidirectional cultural transmission and constructive sociogenesis. In W. de Graaf \& R. Maier (Orgs.), Sociogenesis reexamined (pp. 47-70). Nova York: Springer.

Valsiner, J. (2001). Comparative study of human cultural development. Madri: Fundación Infancia y Aprendizaje.

Villas Boas, B. M. de F. (1995). Reflexões sobre a avaliação e a formação de profissionais da educação. Caderno Linhas Críticas (UnB), 1 (dez), 23-30.

Vygotsky, L. S. (1983). Fundamentos de defectología. Havana, Cuba: Pueblo y Educación.

Vygotsky, L. S. (1987). Pensamento e linguagem. São Paulo: Martins Fontes.

Vygotsky, L. S. (1991). A formação social da mente. São Paulo: Martins Fontes 
Maria Carmen Villela Rosa Tacca, doutora em Psicologia pela Universidade de Brasília, é professora adjunta na Faculdade de Educação da Universidade de Brasília. Endereço para correspondência: SQS 311, Bloco H, Ap. 604; Brasília, DF; CEP: 70364-080. Tel./Fax: (61) 3346-0927, 9817-4817. E-mail: mctacca@yahoo.com.br

Ângela Maria Cristina Uchoa de Abreu Branco, doutora em Psicologia Experimental pela Universidade de São Paulo, é professora adjunta no Instituto de Psicologia da Universidade de Brasília. E-mail: ambranco@terra.com.br 